\title{
Factors for (Un) Sustainable Tourism Development
}

\author{
Maria Vodenska \\ International Business School, \\ 7 Vincent van Gogh Street, 1407 Sofia, Bulgaria; \\ mvodenska@ibsedu.bg
}

Received: 3 February 2020; Revised: 25 March 2020; Accepted: 31 March 2020; Published online: 9 April 2020

\begin{abstract}
The issue of sustainable tourism development is discussed in numerous academic publications and official documents. Nevertheless practical implications of this concept are very rare in tourist destinations in Bulgaria. Sustainable tourism development can be shortly described as a development where the resulting economic and social changes lead to a decrease in the need for environmental protection. Quite a few publications try to identify the factors for destinations' sustainable tourism development. The present research is an attempt to view sustainability as a result of various impacts tourism exerts on the destinations. It can be accepted that positive tourism impacts enhance sustainable tourism development while negative ones can be blamed for the unsustainability of tourist destinations. In their turn tourism impacts are subject to numerous regional and local factors making their monitoring and evaluation extremely difficult but nevertheless indispensable. The present study focuses on three main factors for tourism impacts in destinations in Bulgaria. The three factors investigated are: level of tourism development, stage of tourism development life cycle and prevailing tourism type. But how do we measure tourism impacts and how do me compare them? The impacts in those destinations are evaluated by the local population. This is a way in which all impacts can be compared since they are measured by one and the same indicator - the values they receive from the local population. 5000 questionnaires are distributed and 4397 are processed. One of the most interesting findings shows that the least sustainability can be expected in highly seasonal destinations no matter of the level or the stage of their tourism development It was found out that all three investigated factors are of great importance for the differentiation of local residents' attitude towards tourism, for their perception of tourism impacts and for overall tourism sustainability in general.
\end{abstract}

Key words: Tourism, sustainability, development, factor, evaluation, average value

https://doi.org/10.47246/CEJGSD.2020.2.1.2

\section{| Full text |}

